\title{
$900 \mathrm{MHz}$ Miniaturized Rectenna
}

\author{
A. Okba ${ }^{1}$, A. Takacs ${ }^{1}$, H. Aubert ${ }^{1}$ \\ ${ }^{1}$ LAAS-CNRS, Université de Toulouse, CNRS, INPT, UPS, Toulouse, France \\ Email: aokba@laas.fr; atakacs@laas.fr; aubert@laas.fr
}

\begin{abstract}
This paper addresses the design and the characterization of a new topology of compact rectenna used for electromagnetic energy harvesting of low incident electromagnetic power densities. The rectenna uses a broadband miniaturized flat dipole antenna with a single diode rectifier. The experimental results demonstrate that the efficiency of the proposed compact rectenna is up to $38 \%$ at $900 \mathrm{MHz}$ for electromagnetic power density of $0.26 \mu \mathrm{W} / \mathrm{cm}^{2}$.
\end{abstract}

Index Terms - energy harvesting, rectenna, wireless power transmission, flat dipole antenna.

\section{INTRODUCTION}

Recently, Wireless Power Transfer (WPT) and electromagnetic Energy Harvesting (EH) have become an attractive solution for many industrial applications. The 3D indoor localization is one of these key applications. Nowadays, the 3D localization systems use batteryless tags and beacons in order to derive the position of tagged objects in a warehouse. Batteryless tags collect the power from the surrounding electromagnetic field generated by radiofrequency (RF) dedicated sources. Once enough power is harvested, tags wirelessly transmit their positions to beacons. The beacons communicate with each other through RF signals allowing the system to locate the objects. The RF sources generate the ambient electric field in the $868 \mathrm{MHz}-915 \mathrm{MHz}$ ISM frequency band. A compact rectenna composed of a Flat Dipole Antenna surrounded by a rectangular metallic ring and a rectifier with a single diode is used here to harvest the ambient electromagnetic energy in order to supply the batteryless tags.

In this paper, the broadband Flat Dipole Antenna is presented in section II while the rectifier is studied in section III. The compact rectenna is detailed in the section IV and obtained experimental results are finally discussed.

\section{ANTENNA DESIGN AND RESUlts}

\section{A. Flat Dipole (FD) Antenna}

Recently, broadband dipole antenna topologies have been reported for electromagnetic energy harvesting [1]-[2]. The Flat Dipole shape is carried out by changing the geometry of a standard printed half-wavelength dipole. It is obtained by giving a round shape to the two constitutive quarterwavelength monopoles, as illustrated in Fig. 1. Contrary to the standard dipole where the current density flows along the dipole axis, the current in the shaped dipole flows by following different paths. As sketched in Fig. 1, the current density Js2 goes through a longer path than Js1. As a result, for the same physical length, the lower operating frequency of the antenna is smaller than one of the standard dipole and the antenna bandwidth is increased. In this work, the designed antenna covers the $868 \mathrm{MHz}-915 \mathrm{MHz}$ ISM frequency band. It was rigorously simulated by using the commercial software HFSS [3].

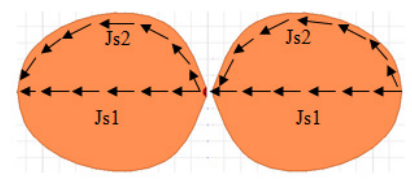

Fig. 1. Sketch of two paths of the current density on the radiating surface of the Flat Dipole Antenna

\section{B. Miniaturization of the Flat Dipole Antrenna}

The miniaturization of antennas can be performed from the use of dielectrics [4], magnetic materials [4], or metamaterials [5]. The modification of the antenna geometry may also be applied (see, e.g., by loading the radiating surface by slit [6], by designing highly irregular antenna profiles [7] or by using coupled ring resonators [8]). The miniaturization of the Flat Dipole Antenna (FDA) is performed here by adding a metallic rectangular ring around the antenna, as shown in Fig. 2. This allows reducing the physical length of the antenna of $25 \%$ while keeping the gain unchanged. Indeed, from appropriate design, the ring may favorably participate to the radiating field by increasing the antenna gain.

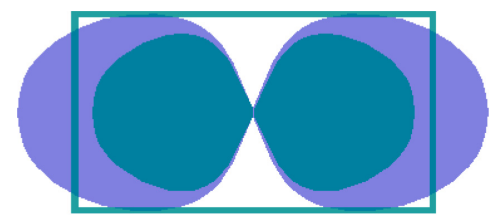

Fig. 2. Layout of the FDAs without rectangular metallic ring (purple) and with the rectangular ring (turquoise blue). The two antennas share the same lower frequency and gain.

The antenna is fabricated by using the lossy FR4 substrate (substrate thickness: $0.8 \mathrm{~mm}$, relative permittivity: 4.4 and loss tangent: 0.02 ). The size is of $10.5 \times 6 \mathrm{~cm}^{2}$. Fig. 3 displays the return loss with and without the rectangular ring. As expected, the ring allows increasing the antenna bandwidth and reducing the physical length of the antenna. The impedance matching is achieved between $840 \mathrm{MHz}$ and $1.2 \mathrm{GHz}$. The radiation pattern is similar to one of the standard half-wavelength dipole with a maximum simulated gain of $2.8 \mathrm{dBi}$ at $900 \mathrm{MHz}$ (see Fig. 4). 


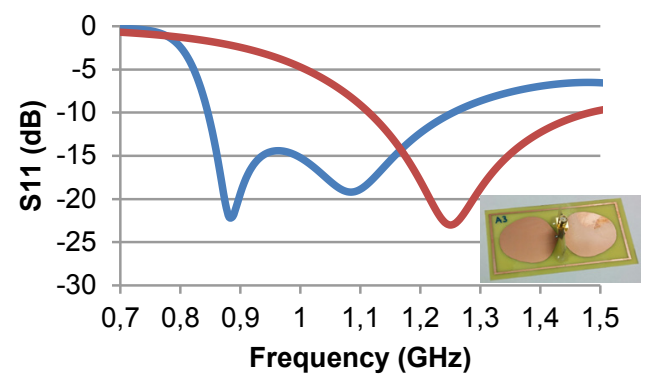

Fig. 3. Simulated return loss as a function of the frequency for the FDA without rectangular ring (red plot) and with rectangular ring (blue plot)

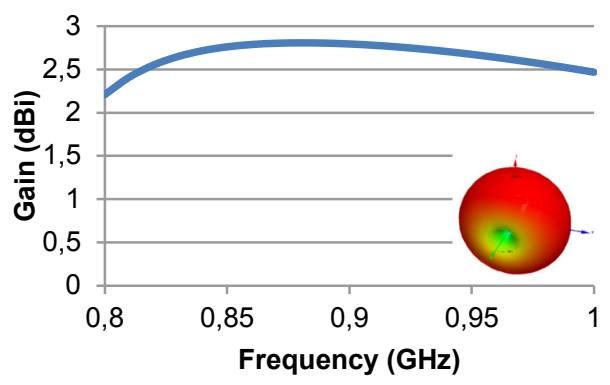

Fig. 4. Simulated maximum gain of the FDA with the rectangular ring as a function of the frequency for $\theta=0^{\circ}$ and $\varphi=0^{\circ}$.

\section{RECTIFIER DESIGN AND RESULTS}

The rectifier was simulated using the commercial software ADS. It is composed by the HSMS2850 Schottky diode mounted in series configuration, a low-pass filter $(100 \mathrm{pF}$ capacitor) used for the filtering of the fundamental and the harmonics and, an adjustable resistive load $(0-10 \mathrm{k} \Omega$ potentiometer). The impedance matching circuit is composed of a shortcircuited stub bent, and a $30 \mathrm{nH}$ inductance for matching the input impedance of the rectifier at $900 \mathrm{MHz}$. Fig. 5 displays the simulated return loss of the rectifier. A good input matching is obtained between $860 \mathrm{MHz}$ and $910 \mathrm{MHz}$.

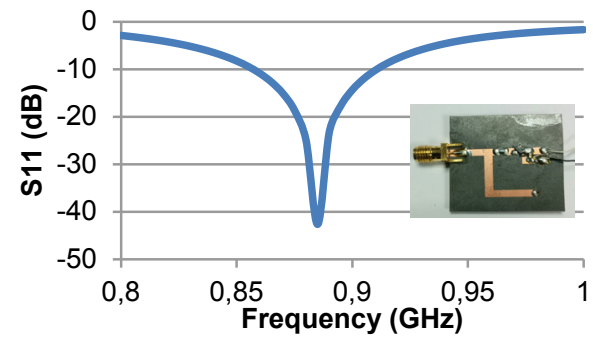

Fig. 5. Simulated return loss of the rectifier as a function of the frequency

The measured DC power is reported in Fig. 6 as a function of the frequency. The DC power of $12 \mu \mathrm{W}$ is measured at 880 $\mathrm{MHz}$ with the $5 \mathrm{k} \Omega$ load (optimal load) and the input RF power of $-15 \mathrm{dBm}$. An acceptable agreement is observed between simulation and measurement results.
The RF-to-DC conversion efficiency can be derived from the following expression:

$$
\eta(\%)=100 \cdot \frac{P_{D C}}{P_{R F}}
$$

where $\mathrm{P}_{\mathrm{DC}}$ is the measured $\mathrm{DC}$ power and $\mathrm{P}_{\mathrm{RF}}$ denotes the $\mathrm{RF}$ power injected at the rectifier input port. The measured and simulated efficiencies are reported in Fig. 7. The obtained maximum efficiency is of $38.6 \%$ at $880 \mathrm{MHz}$.

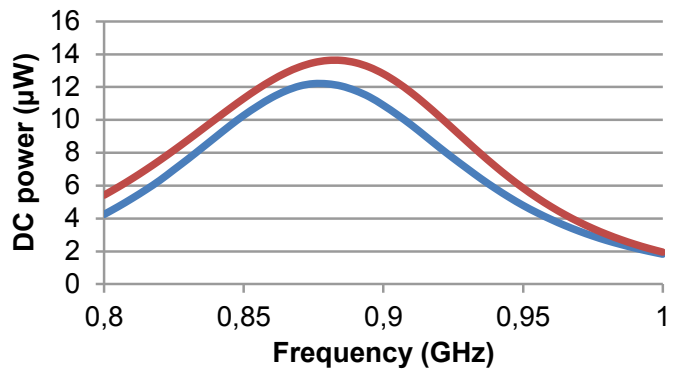

Fig. 6. Measured (blue plot) and simulated (red plot) harvested DC powers as a function of the frequency.

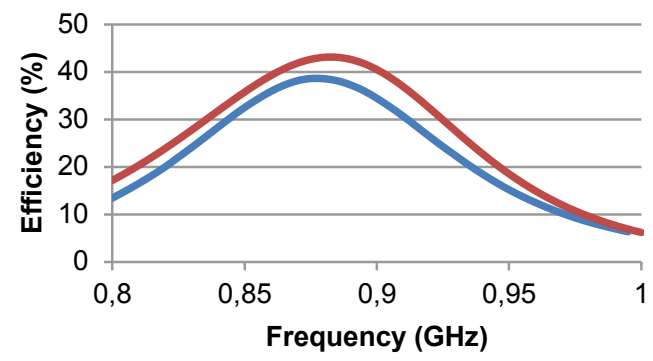

Fig. 7. Measured (blue plot) and simulated (red plot) efficiencies of the rectifier as a function of the frequency

\section{RECTENNA: FABRICATION AND MEASUREMENT RESULTS}

As a first step, the rectifier and the tapered transition for feeding the antenna are assembled and fabricated on the same substrate (Duroïd 5870). The resulting 3D antenna is shown in Fig. 8. Its size is about $10.5 \times 6 \times 7 \mathrm{~cm}^{3}$.

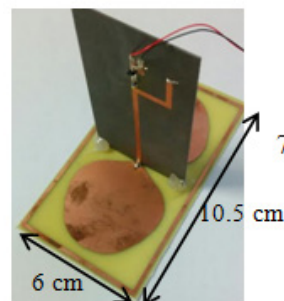

(a)

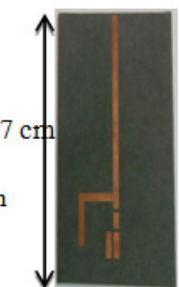

(b)

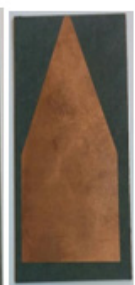

(c)
Fig. 8. The fabricated rectennas: (a) the 3D view of the rectenna (b) top view of the rectifier before mounting the lumped components and (c) bottom view of the rectifier 
The experimental setup is shown in Fig. 9. The Anritsu MG3694B microwave generator is used for injecting the RF signal at the input of the transmitting (Tx) horn antenna (1-12 $\mathrm{GHz}$ ) via a coaxial cable. The horn antenna illuminates the rectenna under test with a linearly-polarized E-field. An automatic acquisition routine is implemented in Labview software from National Instruments to speed-up the acquisition process. The harvested DC voltage is measured by using a standard DC multimeter. The DC power can be derived from the measured DC voltage as long as the load impedance is known. The measured insertion losses due to the coaxial cable are of $1 \mathrm{~dB}$ in the entire frequency band of interest.

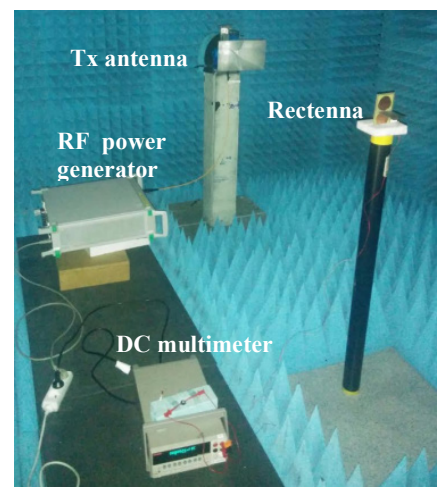

Fig. 9. Experimental setup used to characterize the rectenna

The efficiency of the rectenna can be derived from the following definition:

$$
\eta=\frac{P_{D C}}{S \cdot A_{e f f}} \cdot 10=\frac{4 \cdot \pi \cdot P_{D C}}{S \cdot G_{R} \cdot \lambda^{2}} \cdot 100
$$

where $P_{D C}$ is the harvested DC power, $S$ is the incident $R F$ power density, $A_{\text {eff }}$ is the antenna effective area, $G_{R}$ is the gain of the rectenna's radiating element, and $\lambda$ is the free-space wavelength at the operating frequency. The RF power density $(\mu \mathrm{W} / \mathrm{cm} 2)$ can be determined from the E-field root mean square (rms) value $\mathrm{E}(\mathrm{V} / \mathrm{m})$ on the antenna surface. This field is computed from the RF power Pt injected to the input of the transmitting horn antenna of gain $G_{t}$ located at the distance $d$ from the rectenna. Consequently, the RF power density at the rectenna location is given by:

$$
S=\frac{E^{2}}{120 . \pi} \cdot 10=\frac{30 \cdot P_{t} \cdot G_{t}}{d^{2} \cdot 120 \cdot \pi} \cdot 100
$$

Fig. 10 shows the measured harvested DC power at the input port of the resistive load (RL $=5 \mathrm{k} \Omega$ ) between $800 \mathrm{MHz}$ and $1 \mathrm{GHz}$ for an incident power density ranging from 0.25 $\mu \mathrm{W} / \mathrm{cm}^{2}$ to $0.6 \mu \mathrm{W} / \mathrm{cm}^{2}$. The DC power of $32.6 \mu \mathrm{W}$ is measured at $900 \mathrm{MHz}$ for the incident RF power density of 0.52 $\mu \mathrm{W} / \mathrm{cm}^{2}$.

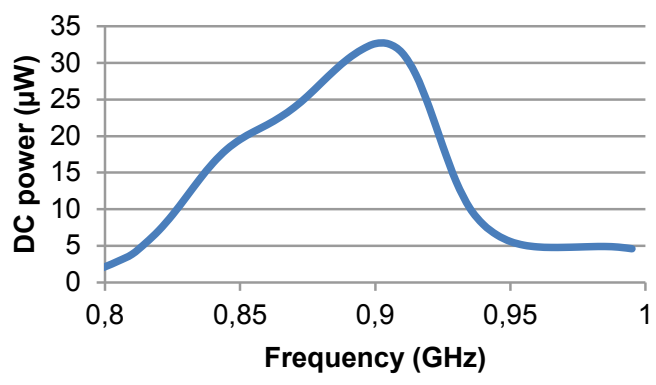

Fig. 10. Measured DC power at the input port of the resistive load $(\mathrm{RL}=300 \Omega)$ as a function of the frequency

The optimal load impedance was also experimentally determined. Fig. 11 shows the DC harvested power as a function of the resistive load value at $900 \mathrm{MHz}$. It can be observed that the maximum DC power is obtained for $\mathrm{R}=5 \mathrm{k} \Omega$.

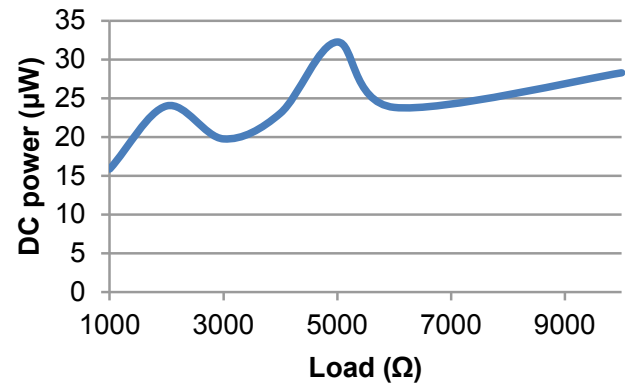

Fig. 11. Measured DC power harvested by the rectenna as a function of the resistive load value at $900 \mathrm{MHz}$

The conversion efficiency of the rectenna is derived from (2). Fig. 12 depicts the RF-to-DC conversion efficiency as a function of the RF power density illuminating the rectenna under test. The efficiency exceeds $30 \%$ for low input RF power densities and reaches $47 \%$ for a power density of 2.1 $\mu \mathrm{W} / \mathrm{cm}^{2}$.

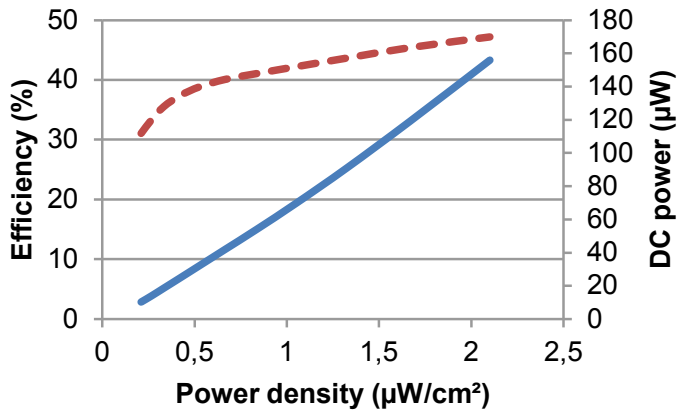

Fig. 12. Rectenna efficiency (red dashed line) at $900 \mathrm{MHz}$ and the harvested DC power (blue continuous line) as a function of illuminating RF power density

Using the load impedance of $10 \mathrm{k} \Omega$, the harvested DC voltage exceeds $330 \mathrm{mV}$ (see Fig. 13) when the RF power density is at least of $0.25 \mu \mathrm{W} / \mathrm{cm}^{2}$ or equivalently, if the RF input power is higher than $-14 \mathrm{dBm}$ at the rectifier input. Conse- 
quently, the proposed rectenna may power-up the BQ25504 DC-DC boost converter [9].

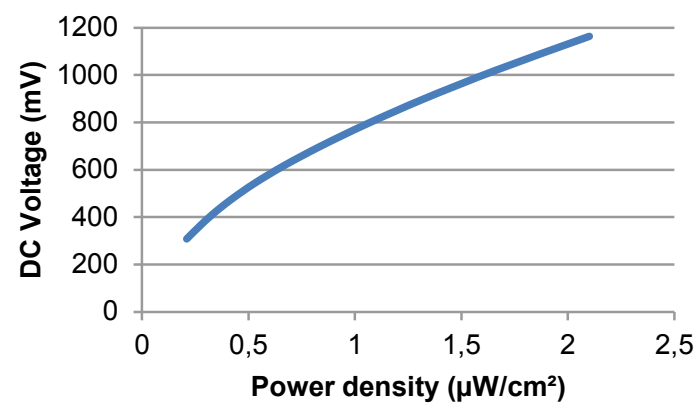

Fig. 13. Harvested DC voltage as a function of the incident RF power density with the load of $10 \mathrm{k} \Omega$

The Table I summarize key performances of the proposed FDA rectenna and of state-of-the-art rectennas operating at the same frequency. It can be observed that the FDA rectenna is the most compact while having a good efficiency for low incident RF power densities. Hence, it is a good candidate for achieving the best trade-off between compactness and efficiency.

\section{TABLE I}

KEY PERFORMANCES OF THE PROPOSED FD RECTENNA AND OF STATE-OF-THE-ART RECTENNAS OPERATING IN THE SAME FREQUENCY BAND

\begin{tabular}{|c|c|c|c|c|}
\hline Ref & $\begin{array}{c}\text { Freq } \\
(\mathrm{GHz})\end{array}$ & $\begin{array}{l}\operatorname{PRF}(\mathrm{dBm}) \\
\mathrm{S}\left(\mu \mathrm{W} / \mathrm{cm}^{2}\right)\end{array}$ & $\eta(\%)$ & $\begin{array}{c}\text { Antenna } \\
\text { surface }\end{array}$ \\
\hline [10] & $\begin{array}{c}0.915 \\
2.45\end{array}$ & $1 \mu \mathrm{W} / \mathrm{cm}^{2}$ & $37 \%$ & $\begin{array}{c}6 \times 6 \mathrm{~cm}^{2} \\
0.33 \lambda 0^{2}\end{array}$ \\
\hline [11] & 0.9 & $10 \mathrm{dBm}$ & $33 \%$ & NR \\
\hline [12] & 0.868 & $-20 \mathrm{dBm}$ & $20 \%$ & NR \\
\hline [13] & 0.9 & $\begin{array}{c}0.1 \mu \mathrm{W} / \mathrm{cm}^{2} \\
1 \mu \mathrm{W} / \mathrm{cm}^{2}\end{array}$ & $\begin{array}{l}16 \% \\
40 \%\end{array}$ & $\begin{array}{c}11 \times 11 \mathrm{~cm}^{2} \\
0.11 \lambda 0^{2}\end{array}$ \\
\hline $\begin{array}{l}\text { In this } \\
\text { work }\end{array}$ & 0.9 & $\begin{array}{c}0.21 \mu \mathrm{W} / \mathrm{cm}^{2} \\
1 \mu \mathrm{W} / \mathrm{cm}^{2}\end{array}$ & $\begin{array}{l}31 \% \\
42 \%\end{array}$ & $\begin{array}{c}11 \times 6 \mathrm{~cm}^{2} \\
0.05 \lambda 0^{2}\end{array}$ \\
\hline
\end{tabular}

NR : Non Reported

\section{CONCLUSION}

In this paper, a new rectenna based on a miniaturized Flat Dipole Antenna $\left(0.05 \lambda 0^{2}\right)$ is proposed. The miniaturization was performed by using a properly designed rectangular metallic ring. The measured efficiency of the fabricated rectenna exceeds $30 \%$ for a RF power density of $0.21 \mu \mathrm{W} / \mathrm{cm}^{2}$ and reaches $47 \%$ for $2.1 \mu \mathrm{W} / \mathrm{cm}^{2}$. Moreover, the rectenna may be used for powering-up a DC-DC boost converter for industrial applications.

\section{BIBLIOGRAPHY}

[1] V. Kuhn, C. Lahuec, F. Seguin, and C. Person, "A Multi-Band Stacked RF Energy Harvester With RF-to-DC Efficiency Up to 84\%," IEEE Trans. Microw. Theory Tech., vol. 63, no. 5, pp. 1768-1778, May 2015.

[2] S. D. Assimonis, S. N. Daskalakis, and A. Bletsas, "Sensitive and Efficient RF Harvesting Supply for Batteryless Backscatter Sensor Networks," IEEE Trans. Microw. Theory Tech., vol. 64, no. 4, pp. 13271338, Apr. 2016.

[3] “ANSYS HFSS." [Online]. Available: http://www.ansys.com/frFR/products/electronics/ansys-hfss. [Accessed: 18-Jul-2017].

[4] VOLAKIS John, CHEN Chi-chi, FUJIMOTO Kyohei, "Small antennas: miniaturization techniques \& applications". McGraw Hill Professional, 2009 . .

[5] R. O. Ouedraogo, E. J. Rothwell, A. R. Diaz, K. Fuchi, and A. Temme, "Miniaturization of Patch Antennas Using a Metamaterial-Inspired Technique," IEEE Trans. Antennas Propag., vol. 60, no. 5, pp. 21752182, May 2012.

[6] B. Ghosh, S. M. Haque, and D. Mitra, "Miniaturization of Slot Antennas Using Slit and Strip Loading," IEEE Trans. Antennas Propag., vol. 59, no. 10, pp. 3922-3927, Oct. 2011.

[7] A. Takacs, N. Fonseca, H. Aubert, "'Height Reduction of the AxialMode Open-Ended Quadrifilar Helical Antenna", IEEE Antennas and Wireless Propagation Letters, vol. 9, pp. 942-945, 2010.

[8] 0. Ripoche, H. Aubert, A. Bellion, P. Pouliguen, P. Potier, Broadband Antenna and Method of Increasing the Bandwidth of a Plane Spiral Antenna, Patent No WO2013121118,

[9] http://www.ti.com/product/BQ25504

[10] K. Niotaki, S. Kim, S. Jeong, A. Collado, A. Georgiadis, and M. M. Tentzeris, "A Compact Dual-Band Rectenna Using Slot-Loaded Dual Band Folded Dipole Antenna," IEEE Antennas Wirel. Propag. Lett., vol. 12, pp. 1634-1637, 2013.

[11] D. Masotti, A. Costanzo, P. Francia, M. Filippi, and A. Romani, "A Load-Modulated Rectifier for RF Micropower Harvesting With StartUp Strategies," IEEE Trans. Microw. Theory Tech., vol. 62, no. 4, pp. 994-1004, Apr. 2014.

[12] S. D. Assimonis and A. Bletsas, "Energy harvesting with a low-cost and high efficiency rectenna for low-power input," in 2014 IEEE Radio and Wireless Symposium (RWS), 2014, pp. 229-231.

[13] V. Palazzi, J. Hester, J. Bito, F. Alimenti, , C. Kalialakis, A. Collado, P. Mezzanotte, A. Georgiadis, L. Roselli, M. M. Tentzeris, 'Novel UltraLightweight Multiband Rectenna on Paper for RF Energy Harvesting in the Next Generation LTE Bands', IEEE Trans. Microw. Theory Tech., vol. pp, issue 99 . 